\title{
Impact of annealing on performance of X-ray mirror coatings for Athena
}

Henriksen, P. L.; Ferreira, D. D.M.; Massahi, S.; Svendsen, S.; Gellert, N.; Christensen, F. E.; Jegers, A. S.; Landgraf, B.; Thete, A.; Collon, M.

Total number of authors:

17

Published in:

Proceedings of SPIE

Link to article, DOI:

$10.1117 / 12.2594559$

Publication date:

2021

Document Version

Publisher's PDF, also known as Version of record

Link back to DTU Orbit

Citation (APA):

Henriksen, P. L., Ferreira, D. D. M., Massahi, S., Svendsen, S., Gellert, N., Christensen, F. E., Jegers, A. S., Landgraf, B., Thete, A., Collon, M., Handick, E., Cibik, L., Krumrey, M., Gollwitzer, C., Ferreira, I., Shortt, B., \& Bavdaz, M. (2021). Impact of annealing on performance of X-ray mirror coatings for Athena. In S. L. O'Dell, J. A. Gaskin, \& G. Pareschi (Eds.), Proceedings of SPIE: Optics for EUV, X-Ray, and Gamma-Ray Astronomy $X$ [118220D] SPIE - International Society for Optical Engineering. Proceedings of SPIE - The International Society for Optical Engineering Vol. 11822 https://dol.org/10.1117/12.2594559

\section{General rights}

Copyright and moral rights for the publications made accessible in the public portal are retained by the authors and/or other copyright owners and it is a condition of accessing publications that users recognise and abide by the legal requirements associated with these rights.

- Users may download and print one copy of any publication from the public portal for the purpose of private study or research.

- You may not further distribute the material or use it for any profit-making activity or commercial gain

- You may freely distribute the URL identifying the publication in the public portal 


\title{
Impact of annealing on performance of X-ray mirror coatings for Athena
}

\author{
P. L. Henriksen ${ }^{\text {a }}$, D. D. M. Ferreira ${ }^{a}$, S. Massahi ${ }^{\mathrm{a}}$, S. Svendsen ${ }^{\mathrm{a}}$, N. Gellert ${ }^{\mathrm{a}}$, F. E.

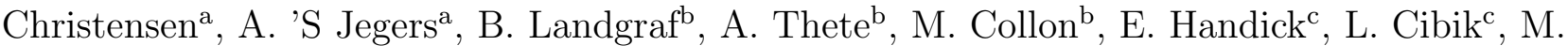

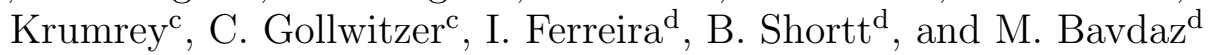 \\ ${ }^{a}$ DTU Space, Technical University of Denmark, Elektrovej, Bygn. 327, 2800, Kgs. Lyngby, \\ Denmark \\ ${ }^{\mathrm{b}}$ cosine Research, Oosteinde 36, 2361 HE Warmond, The Netherlands \\ ${ }^{c}$ Physikalisch-Technische Bundesanstalt (PTB), Abbestr. 2-12, 10587 Berlin, Germany \\ ${ }^{\mathrm{d} E S T E C}$, European Space Research and Technology Centre, Keplerlaan 1, 2201 AZ \\ Noordwijk, The Netherlands
}

\begin{abstract}
As part of the manufacturing process of mirror modules for the Athena X-ray telescope, Silicon Pore Optics plates are assembled into mirror module stacks. The plates that form each stack are held together by direct bonding, relying on van der Waals forces and covalent bonds for adhesion. One way to increase the strength of the covalent bonds is through annealing of the mirror stacks. It is of critical importance to the mission to ensure compatibility between the reflective coating and any post-coating processing of the plates. We present our findings of the impact of annealing on the X-ray reflectance of coated mirrors relevant for the Athena mission. These are Ir single layers, as well as $\mathrm{Ir} / \mathrm{B}_{4} \mathrm{C}, \mathrm{Ir} / \mathrm{SiC}$, and $\mathrm{Ir} / \mathrm{C}$ bilayers. We investigate the effect on the performance of the coatings after annealing at atmospheric pressure and at a low vacuum using $\mathrm{X}$-ray reflectometry. $\mathrm{B}_{4} \mathrm{C}$ is found to suffer degradation from annealing under atmospheric conditions but not when annealed in vacuum. All other materials investigated are robust to atmospheric annealing.
\end{abstract}

Keywords: Athena, X-ray mirrors, reflective coatings, annealing, X-ray reflectometry

\section{INTRODUCTION}

The Advanced Telescope for High-Energy Astropysics (Athena) is a large-class ESA selected mission aimed at studying the hot and energetic Universe. ${ }^{1}$ The X-ray optics will be based on Silicon Pore Optics (SPO) technology and consist of more than 100,000 plates individually coated and stacked to form the complete mirror assembly. The stacking of the SPO plates must ensure that the plates are bonded with a strength sufficient to withstand the forces involved with the launch. Prior to deposition of the X-ray reflective coating, stripes of photoresist are deposited on the plates that, upon removal, expose part of the plates to allow for direct stacking. After coating deposition, the photoresist stripes are chemically lifted using a dimethyl sulfoxide (DMSO) bath. ${ }^{2}$ The surfaces are cleaned using an SC-1 recipe, ${ }^{3}$ allowing for direct hydrophilic bonding.

While direct silicon-to-silicon bonding can occur at room temperature, the surfaces are initially held together by relatively weak van der Waals forces and hydrogen bonding. They can, however, form stronger covalent bonds through annealing at elevated temperatures, where the bonding strength can be gradually increased through thermal annealing until the bulk fracture strength of $\mathrm{Si}$ is reached above $1000{ }^{\circ} \mathrm{C} .{ }^{4}$ Since stacking occurs after the coating deposition, it is crucial that any subsequent processing step such as annealing does not compromise the performance of the coating. There are methods to improve bonding at more moderate temperatures. For example the surfaces can be put under ultra-high-vacuum to ensure they are free of adsorbate layers and thus

Further author information - send correspondence to:

Peter Lindquist Henriksen, e-mail: plihen@space.dtu.dk

Optics for EUV, X-Ray, and Gamma-Ray Astronomy X, edited by Stephen L. O'Dell,

Jessica A. Gaskin, Giovanni Pareschi, Proc. of SPIE Vol. 11822, 118220D · ()

2021 SPIE · CCC code: 0277-786X/21/\$21 - doi: 10.1117/12.2594559

Proc. of SPIE Vol. 11822 118220D-1 
form a stronger bond. Alternatively, chemical surface activation by oxygen plasma exposure can help to achieve higher bonding strengths, just as annealing at moderate temperatures $\left(200-500{ }^{\circ} \mathrm{C}\right)$ has been shown to increase the bonding strength between oxidized silicon wafers. ${ }^{5}$

Studies of thermal cycles simulating low-Earth orbit temperature fluctuations on $\mathrm{W} / \mathrm{B}_{4} \mathrm{C}$ multilayers found, however, that the enhanced temperatures have a slight negative influence on mirror reflectance at $1.5 \mathrm{keV}$, corresponding to an increase in interface roughness. ${ }^{6}$ In this paper the compatibility of the Athena candidate coatings ( $\mathrm{Ir}, \mathrm{Ir} / \mathrm{SiC}, \mathrm{Ir} / \mathrm{B}_{4} \mathrm{C}$, and $\mathrm{Ir} / \mathrm{C}$ ) with a thermal annealing procedure aiming to improve SPO plate bonding strength is investigated.

\section{EXPERIMENTAL PROCEDURE}

For this study samples were prepared with reflective coatings with each of the Athena optics candidate material combinations. Sets of mirror samples were created where one was kept as reference and its partner sample underwent annealing. The pairs of samples were measured using X-ray reflecometry (XRR) at $1.487 \mathrm{keV}$ and $8.048 \mathrm{keV}$ prior to annealing and at regular time intervals after annealing to study the temporal stability of the coatings and identify any long-term effects caused by the annealing procedure.

\subsection{Sample preparation}

The substrates used were rectangular plates of $70 \times 10 \mathrm{~mm}^{2}$ cut out of $200 \mathrm{~mm}$ double side super polished Si wafers. The sample sets were mounted in close proximity to each other on the carriers to ensure maximal coating uniformity. They were plasma cleaned in-situ and coated at a pressure of $3.4 \times 10^{-3}$ mbar using DC magnetron sputtering at the Silicon Pore Optics coating facility for the Athena mission. ${ }^{7}$

\subsubsection{Sample annealing}

Annealing was carried out at DTU Space using a Lab Companion OV-11 vacuum-compatible oven following specifications defined by cosine Research BV. The annealing procedure calls for annealing carried out in a constant atmosphere at ambient pressure. The samples are brought to a temperature of $200{ }^{\circ} \mathrm{C}$ over a two-hour period and kept there for 50 hours. The samples are allowed to slowly cool off for 8 hours before the oven is opened and the annealed sample can be characterized.

Following the results observed on some samples annealed under atmospheric conditions, low-vacuum annealing on additional samples was carried out to determine the effect of atmospheric annealing to that in a low-pressure environment. For vacuum annealing a Varian SH-100 dry oil-free pump with a pumping spead of $83 \mathrm{lpm}$ and an ultimate pressure of $6.6 \times 10^{-2}$ mbar was used. ${ }^{8}$ The reachable pressure is dependent on the vacuum chamber and the vacuum hose but a reasonable estimate is that the pressure reached was around $10^{-1}$ mbar. The vapor pressure of water at room temperature is on the order of 20 mbar. Table 1 gives an overview of the samples used for this study.

Table 1: List of samples and associated coatings used in this work.

\begin{tabular}{lcccccc}
\hline Reflector & $10 \mathrm{~nm} \mathrm{Ir}$ & $30 \mathrm{~nm} \mathrm{Ir}$ & $30 \mathrm{~nm} \mathrm{Ir}$ & $20 \mathrm{~nm} \mathrm{Ir}$ & $30 \mathrm{~nm} \mathrm{Ir}$ & $10 \mathrm{~nm} \mathrm{Ir}$ \\
Overcoat & - & - & $12 \mathrm{~nm} \mathrm{~B}_{4} \mathrm{C}$ & $8 \mathrm{~nm} \mathrm{~B} \mathrm{~B}_{4} \mathrm{C}$ & $4 \mathrm{~nm} \mathrm{SiC}$ & $8 \mathrm{~nm} \mathrm{C}$ \\
\hline Reference sample & $\operatorname{cs} 00096$ & $\operatorname{cs} 00108$ & $\operatorname{cs} 00148$ & $\operatorname{cs} 00144$ & $\operatorname{cs} 00135$ & $\operatorname{cs} 00190$ \\
Atmospheric annealing & $\operatorname{cs} 00098$ & $\operatorname{cs} 00110$ & $\operatorname{cs} 00149$ & - & $\operatorname{cs} 00134$ & $\operatorname{cs} 00193$ \\
Vacuum annealing & - & - & - & $\operatorname{cs} 00145$ & - & $\operatorname{cs} 00192$ \\
\hline
\end{tabular}

\subsection{Sample characterization}

Characterization of the treated and reference samples was carried out using X-ray reflectometry (XRR) before annealing and immediately after annealing, as well as after 1 week, 1 month, 3 months, and 6 months. Although measurements were taken at regular intervals following annealing, the effect of annealing on mirror reflectance was immediate with no temporal evolution, so for clarity, only one measurement post-annealing at +6 months will be shown in the results section. 


\subsubsection{X-ray reflectometer facilities}

Specular $\theta-2 \theta$ measurements were carried out using the Low-Energy X-ray Reflectometer (LEXR) operating at $1.487 \mathrm{keV}^{9}$ and a Rigaku XRD Smartlab operating at $8.048 \mathrm{keV}$. The low-energy measurements are crucial for identifying any changes to the low-density overcoat and at the same time represents a data point close to the $1 \mathrm{keV}$ effective area requirement of Athena. A step size of 50 mdeg and a range in $\theta$ of $0-15$ deg was used for the specular measurements and the system has a beam divergence $<12.5$ mdeg. LEXR was also used to obtain measurements of the non-specular scattering. Scatter measurements were carried out around specular peaks at about 4 deg using a detector slit of $1 \mathrm{~mm}$, corresponding to an angular acceptance of 0.14 deg. LEXR uses a 2D CCD detector with a pixel pitch of $26 \mu \mathrm{m}$. The error bars on LEXR data represent only statistical uncertainties and thus underestimate the total errors.

Measurements at $8.048 \mathrm{keV}$ easily penetrate the overcoat and primarily yield information about the high-density reflector underneath. For these measurements a step size of 15 mdeg and a range in $\theta$ of $0-3$ deg was used. The Smartlab uses a D/teX Ultra 1D detector and an angular resolution of 7 mdeg was assumed for measurements with this system.

In addition to the fixed-energy measurements carried out at $1.487 \mathrm{keV}$ and $8.048 \mathrm{keV}$, samples were measured at incidence angles of $0.6 \mathrm{deg}$ and $1 \mathrm{deg}$ in the energy range $3.4-10 \mathrm{keV}$ at the Four-Crystal-Monochromator (FCM) beamline of the PTB laboratory at the BESSY II synchrotron radiation facility. The energy resolution is $<1 \mathrm{eV}$ and measurements were performed using the $4.5 \times 4.5 \mathrm{~mm}^{2} \mathrm{GaP}$ diode detector. ${ }^{10}$

\subsubsection{Fitting of XRR data}

Data was analyzed using the IMD software ${ }^{11}$ with optical constants from The Center for X-Ray Optics at Lawrence Berkeley National Laboratory. ${ }^{12}$ The models used consist of an Si substrate with a $2.5 \mathrm{~nm}$ layer of native $\mathrm{SiO}_{2}{ }^{13}$ where, to reduce model complexity, the roughness of the $\mathrm{SiO}_{2}$ layer is coupled to that of the substrate-oxide interface. On the Ir single layers, a hydrocarbon overlayer of density $1 \mathrm{~g} / \mathrm{cm}^{3}$ and surface roughness coupled to that of the overlayer-Ir interface is included in the model to account for the naturally occuring contamination layer. For all samples with a deposited low-Z overcoating, thickness $z$, density $\rho$, and roughness $\sigma$ are fitted independently of the Ir undercoat.

\section{RESULTS AND DISCUSSION}

The results of the annealing study are presented in this section. First the temporal stability of the coatings is demonstrated by comparing XRR measurements of the reference samples taken shortly after coating and 6 months after annealing of their sample pairs. Secondly, the impact of annealing on both specular and nonspecular XRR measurements is shown. The effect of an overlayer degradation on the specular reflectance at $1.487 \mathrm{keV}$ is simulated, and finally, we investigate the reflectance of the samples in the energy range $3.4-10 \mathrm{keV}$. 


\subsection{Temporal stability of mirror coatings}

The untreated reference samples were monitored over a period ranging from prior to annealing of the pairs to 6 months after the thermal treatment. Figure 1 shows XRR measurements at $1.487 \mathrm{keV}$ and $8.048 \mathrm{keV}$ for each of the six reference samples over the six month period of this study.
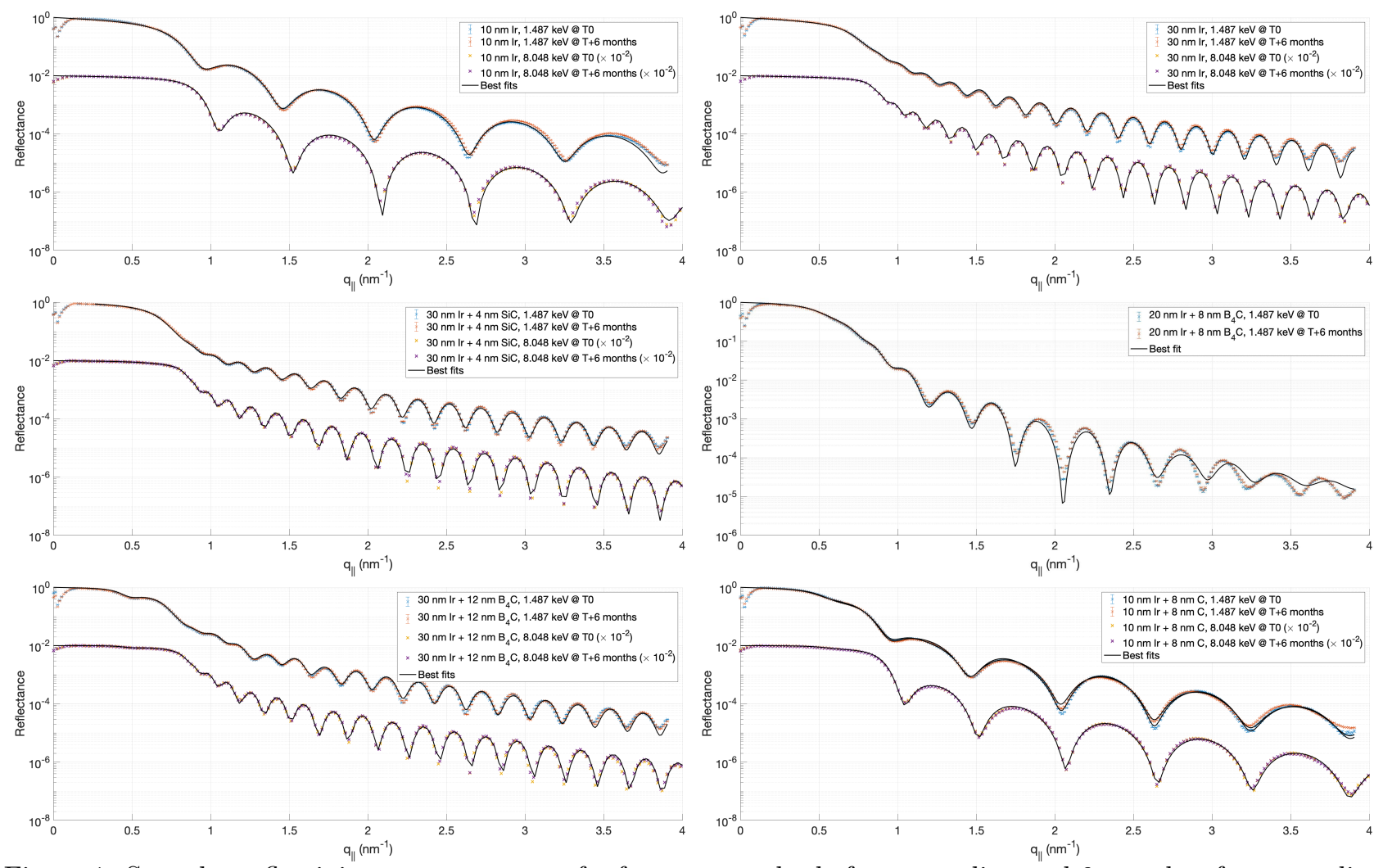

Figure 1: Specular reflectivity measurements of reference samples before annealing and 6 months after annealing of treatment samples plotted in reciprocal space. $8.048 \mathrm{keV}$ measurements of the $20 / 8 \mathrm{~nm} \mathrm{Ir} / \mathrm{B}_{4} \mathrm{C}$ samples are not available.

Note the presence of a double critical angle on the $1.487 \mathrm{keV}$ measurements due to the low-density overlayers, particularly evident on the sample with a $12 \mathrm{~nm} \mathrm{~B}_{4} \mathrm{C}$ overcoat. The best-fit parameters are listed in Table 2 . Since no time-dependent evolution was observed on the reference samples, any change on the annealed pairs must be an effect of the annealing itself rather than temporal.

\subsection{Impact of annealing on sample reflectance}

Upon removal of sample cs00149 from the oven, it was immediately apparent that the $\mathrm{B}_{4} \mathrm{C}$ was altered by the treatment. Figure 2 shows an optical image of the sample and its reference. As no change had been observed on the annealed $\mathrm{Ir} / \mathrm{SiC}$, visually or in XRR measurements, annealing under low-vacuum was performed only on another $\mathrm{Ir} / \mathrm{B}_{4} \mathrm{C}$ sample as well as on an $\mathrm{Ir} / \mathrm{C}$ sample.

Figure 3 shows the effect of annealing on the X-ray reflectance of the samples. The best-fit parameters are listed in Table 2 along with those for the reference samples. Note that the overcoat parameters are difficult to constrain at $8.048 \mathrm{keV}$ due to their limited reflectance at this energy and the strong signal from the Ir coating.

Both the $10 \mathrm{~nm}$ and $30 \mathrm{~nm}$ Ir coatings were unaffected by the annealing procedure. Iridium has, in fact, been found to be unaffected by the full stacking procedure, including chemical processing and annealing. ${ }^{14}$ The $\mathrm{Ir} / \mathrm{SiC}$ bilayer was also found to be robust to the thermal treatment with a possible positive effect in terms of a reduction of the $\mathrm{SiC}$ roughness, which is in agreement with previous results obtained from coatings deposited at 


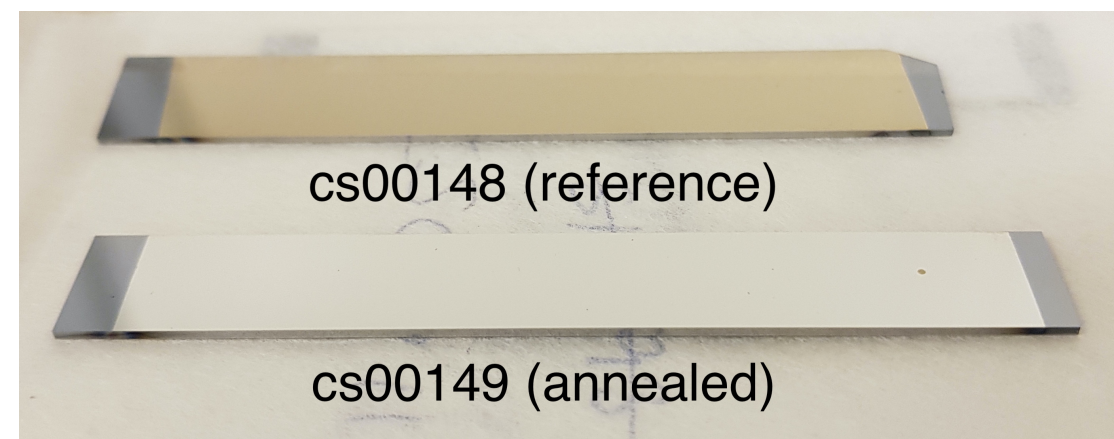

Figure 2: Optical image showing absence of the distinct yellow tint of the $\mathrm{B}_{4} \mathrm{C}$ on the annealed sample.
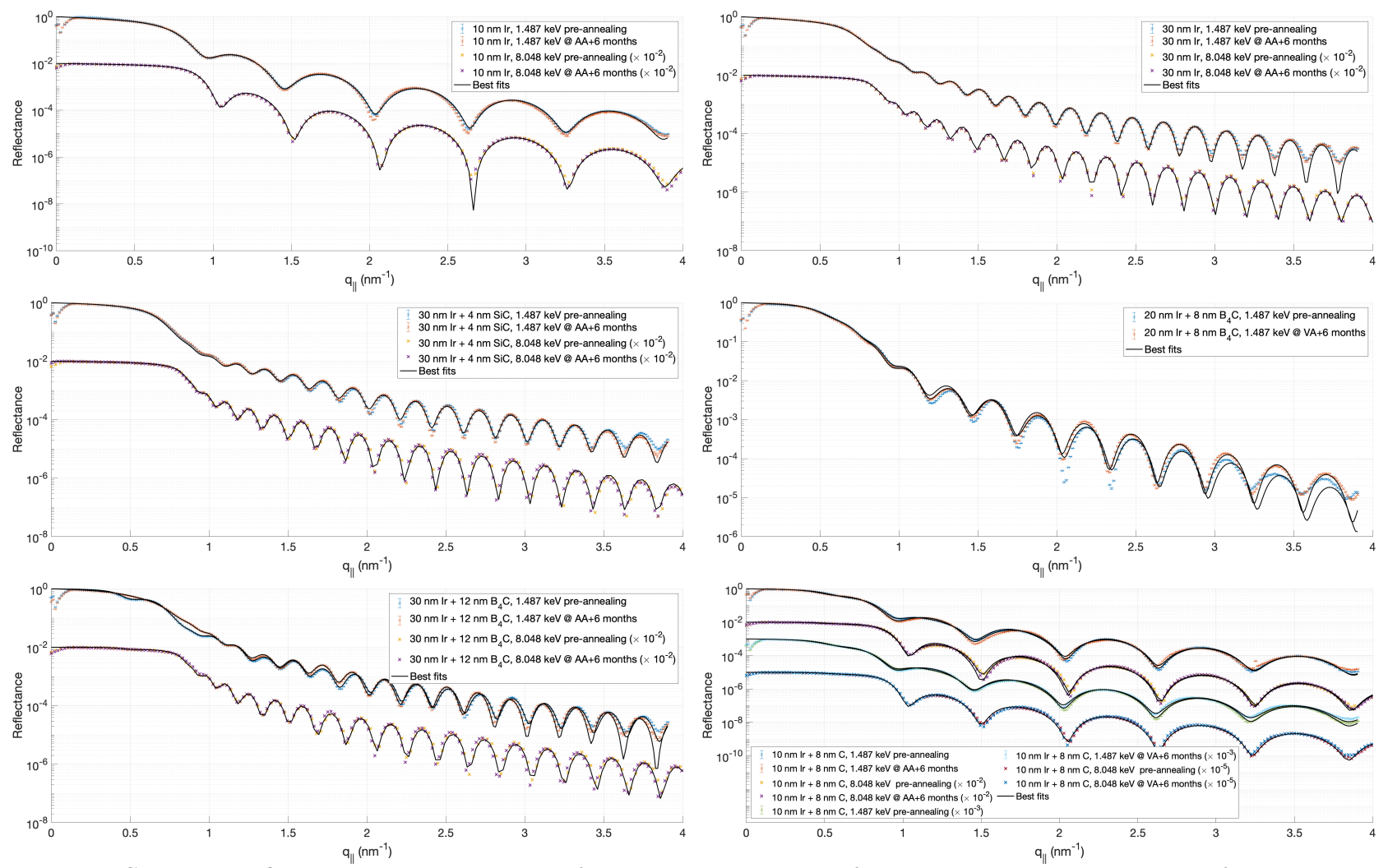

Figure 3: Specular reflectivity measurements of annealing samples before annealing and 6 months after annealing plotted in reciprocal space. AA denotes atmospheric annealing and VA denotes vacuum annealing. $8.048 \mathrm{keV}$ measurements of the $20 / 8 \mathrm{~nm} \mathrm{Ir} / \mathrm{B}_{4} \mathrm{C}$ samples are not available.

DTU Space. ${ }^{15}$ The $\mathrm{Ir} / \mathrm{B}_{4} \mathrm{C}$ bilayer annealed under atmospheric conditions underwent drastic changes, similar to previous observations. ${ }^{16}$ The XRR measurements post-annealing resembles those of an Ir single layer without an overcoat and the best-fit parameters indicate a $\mathrm{B}_{4} \mathrm{C}$ layer with significantly reduced thickness and density. Drawing further conclusions on the characteristics of the annealed $\mathrm{B}_{4} \mathrm{C}$ is not possible from $\mathrm{XRR}$ fitting alone, as we are modelling a layer that might be patchy or not present at all. After vacuum annealing of the $\operatorname{Ir} / \mathrm{B}_{4} \mathrm{C}$ it was not possible by eye to see a difference in the coating as was the case for atmospheric annealing. Post-annealing XRR measurements show a larger fringe amplitude at large incidence angles than before annealing. It is not clear from the XRR fits what causes this difference but other characterization methods such as X-ray photoelectron spectroscopy could be used to gain further insight into the effect of both atmospheric and vaccum annealing $\mathrm{B}_{4} \mathrm{C}$. Atmospheric or vacuum annealing of the Ir/C had no effect on performance compared to the reference sample. 
Table 2: Best-fit parameters to reference and annealed samples. The overcoat (OC) on Ir single layers at 1.487 $\mathrm{keV}$ are the naturally occurring hydrocarbons rather than an intentionally deposited coating. ${ }^{*}$ Indicates a fixed parameter.

\begin{tabular}{|c|c|c|c|c|c|c|c|c|c|}
\hline $\begin{array}{l}\text { Overcoat } \\
\text { (OC) }\end{array}$ & Sample & $\begin{array}{l}\text { XRR } \\
\text { Energy }\end{array}$ & $\begin{array}{l}\text { Measurement } \\
\text { time }\end{array}$ & $\begin{array}{l}\mathrm{OC} z \\
(\mathrm{~nm})\end{array}$ & $\begin{array}{c}\mathrm{OC} \rho \\
\left(\mathrm{g} / \mathrm{cm}^{3}\right)\end{array}$ & $\begin{array}{l}\mathrm{OC} \sigma \\
(\mathrm{nm})\end{array}$ & $\begin{array}{l}\operatorname{Ir} z \\
(\mathrm{~nm})\end{array}$ & $\begin{array}{l}\operatorname{Ir} \sigma \\
(\mathrm{nm})\end{array}$ & $\begin{array}{r}\text { Sub } \sigma \\
(\mathrm{nm})\end{array}$ \\
\hline \multirow{8}{*}{ None } & \multirow[b]{2}{*}{$\operatorname{cs} 00096$} & \multirow{2}{*}{$1.487 \mathrm{keV}$} & Pre-annealing & 1.8 & $1.00^{*}$ & $\operatorname{Ir} \sigma$ & 9.9 & 0.29 & 0.33 \\
\hline & & & +6 months & 1.8 & $1.00^{*}$ & $\operatorname{Ir} \sigma$ & 9.9 & 0.26 & 0.29 \\
\hline & \multirow[t]{2}{*}{ Reference } & \multirow{2}{*}{$8.048 \mathrm{keV}$} & Pre-annealing & - & - & - & 9.8 & 0.37 & 0.16 \\
\hline & & & +6 months & - & - & - & 9.9 & 0.37 & 0.16 \\
\hline & \multirow[b]{2}{*}{$\operatorname{cs} 00098$} & \multirow{2}{*}{$1.487 \mathrm{keV}$} & Pre-annealing & 1.6 & $1.00^{*}$ & $\operatorname{Ir} \sigma$ & 9.9 & 0.27 & 0.32 \\
\hline & & & +6 months & 1.5 & $1.00^{*}$ & $\operatorname{Ir} \sigma$ & 10.0 & 0.30 & 0.28 \\
\hline & \multirow{2}{*}{$\begin{array}{l}\text { Atmospheric } \\
\text { annealed }\end{array}$} & \multirow{2}{*}{$8.048 \mathrm{keV}$} & Pre-annealing & - & - & - & 9.9 & 0.37 & 0.17 \\
\hline & & & +6 months & - & - & - & 9.9 & 0.37 & 0.21 \\
\hline \multirow{8}{*}{ None } & \multirow{4}{*}{$\begin{array}{l}\text { cs00108 } \\
\text { Reference }\end{array}$} & \multirow{2}{*}{$1.487 \mathrm{keV}$} & Pre-annealing & 1.8 & $1.00^{*}$ & Ir $\sigma$ & 30.2 & 0.36 & 0.29 \\
\hline & & & +6 months & 2.1 & $1.00^{*}$ & $\operatorname{Ir} \sigma$ & 30.2 & 0.36 & 0.25 \\
\hline & & \multirow{2}{*}{$8.048 \mathrm{keV}$} & Pre-annealing & - & - & - & 30.1 & 0.41 & 0.17 \\
\hline & & & +6 months & - & - & - & 30.1 & 0.40 & 0.17 \\
\hline & \multirow[b]{2}{*}{$\operatorname{cs} 00110$} & \multirow{2}{*}{$1.487 \mathrm{keV}$} & Pre-annealing & 1.7 & $1.00^{*}$ & Ir $\sigma$ & 30.4 & 0.34 & 0.29 \\
\hline & & & +6 months & 1.8 & $1.00^{*}$ & $\operatorname{Ir} \sigma$ & 30.5 & 0.37 & 0.24 \\
\hline & \multirow{2}{*}{$\begin{array}{l}\text { Atmospheric } \\
\text { annealed }\end{array}$} & \multirow{2}{*}{$8.048 \mathrm{keV}$} & Pre-annealing & - & - & - & 30.4 & 0.41 & 0.16 \\
\hline & & & +6 months & - & - & - & 30.4 & 0.42 & 0.19 \\
\hline \multirow{8}{*}{$\mathrm{SiC}$} & \multirow{4}{*}{$\begin{array}{l}\text { cs00135 } \\
\text { Reference }\end{array}$} & \multirow{2}{*}{$1.487 \mathrm{keV}$} & Pre-annealing & 4.2 & 3.18 & 0.88 & 29.9 & 0.24 & 0.34 \\
\hline & & & +6 months & 4.3 & 3.07 & 0.96 & 29.9 & 0.26 & 0.33 \\
\hline & & $8048 \mathrm{koV}$ & Pre-annealing & 4.2 & 3.19 & 0.86 & 29.9 & 0.29 & 0.30 \\
\hline & & $8.048 \mathrm{keV}$ & +6 months & 4.3 & 3.17 & 1.03 & 29.9 & 0.29 & 0.31 \\
\hline & & $1487 \mathrm{koV}$ & Pre-annealing & 3.9 & 3.20 & 1.13 & 29.9 & 0.27 & 0.35 \\
\hline & $\operatorname{cs} 00134$ & $1.48 \mathrm{reV}$ & +6 months & 4.0 & 2.84 & 0.71 & 30.0 & 0.31 & 0.34 \\
\hline & Atmospheric & $8048 \mathrm{koV}$ & Pre-annealing & 4.1 & 3.21 & 1.05 & 30.0 & 0.31 & 0.34 \\
\hline & annealed & $8.048 \mathrm{keV}$ & +6 months & 4.0 & 3.12 & 0.89 & 30.1 & 0.40 & 0.23 \\
\hline & $\operatorname{cs} 00144$ & & Pre-annealing & 8.3 & 2.27 & 1.09 & 19.6 & 0.60 & 0.10 \\
\hline & Reference & $1.487 \mathrm{keV}$ & +6 months & 8.7 & 2.87 & 1.42 & 19.6 & 0.38 & 0.41 \\
\hline & $\operatorname{cs} 00145$ & $1487 \mathrm{koV}$ & Pre-annealing & 8.2 & 2.25 & 0.93 & 19.7 & 0.37 & 0.41 \\
\hline & Vac. annealed & $1.48 \mathrm{rev}$ & +6 months & 8.8 & 2.70 & 1.77 & 19.8 & 0.29 & 0.33 \\
\hline & & $1487 \mathrm{koV}$ & Pre-annealing & 12.9 & 2.42 & 0.82 & 29.9 & 0.23 & 0.30 \\
\hline $\mathrm{B}, \mathrm{C}$ & $\operatorname{cs} 00148$ & $1.48 \mathrm{rev}$ & +6 months & 12.9 & 2.43 & 1.03 & 29.8 & 0.23 & 0.29 \\
\hline$D_{4}$ & Reference & & Pre-annealing & 12.9 & 2.59 & 0.76 & 29.9 & 0.25 & 0.31 \\
\hline & & $8.048 \mathrm{keV}$ & +6 months & 13.1 & 2.68 & 0.74 & 29.9 & 0.25 & 0.31 \\
\hline & & $1487 \mathrm{koV}$ & Pre-annealing & 12.6 & 2.56 & 1.04 & 29.9 & 0.25 & 0.32 \\
\hline & $\operatorname{cs} 00149$ & $1.48 \mathrm{rev}$ & +6 months & 7.6 & 1.08 & 0.37 & 30.1 & 0.34 & 0.24 \\
\hline & Atmospheric & $8048 \mathrm{koV}$ & Pre-annealing & 12.5 & 2.68 & 0.99 & 29.9 & 0.27 & 0.32 \\
\hline & annealed & $8.048 \mathrm{keV}$ & +6 months & 7.6 & 1.96 & 0.52 & 30.0 & 0.29 & 0.30 \\
\hline & & $1487 \mathrm{loV}$ & Pre-annealing & 8.3 & 2.28 & 0.82 & 9.9 & 0.23 & 0.34 \\
\hline & $\operatorname{cs} 00190$ & $1.48 \mathrm{reV}$ & +6 months & 8.7 & 2.32 & 1.11 & 9.9 & 0.21 & 0.36 \\
\hline & Reference & $8048 \mathrm{koV}$ & Pre-annealing & 8.3 & 2.50 & 0.79 & 9.9 & 0.25 & 0.33 \\
\hline & & $8.048 \mathrm{keV}$ & +6 months & 8.3 & 2.55 & 0.94 & 9.9 & 0.25 & 0.34 \\
\hline & & $1487 \mathrm{roV}$ & Pre-annealing & 8.4 & 2.10 & 0.76 & 9.9 & 0.23 & 0.31 \\
\hline$C$ & $\operatorname{cs} 00193$ & $1.48 \mathrm{r} \mathrm{keV}$ & +6 months & 9.6 & 2.36 & 1.83 & 9.9 & 0.19 & 0.33 \\
\hline 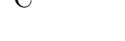 & Atmospheric & & Pre-annealing & 8.4 & 2.52 & 0.84 & 9.9 & 0.25 & 0.33 \\
\hline & annealed & $8.048 \mathrm{keV}$ & +6 months & 10.6 & 2.11 & 0.59 & 10.0 & 0.25 & 0.32 \\
\hline & & $1487 \mathrm{koV}$ & Pre-annealing & 8.6 & 2.24 & 0.90 & 10.0 & 0.25 & 0.32 \\
\hline & $\operatorname{cs} 00192$ & $1.48 \mathrm{keV}$ & +6 months & 9.2 & 2.30 & 1.41 & 10.0 & 0.16 & 0.34 \\
\hline & Vacuum & $8048 \mathrm{koV}$ & Pre-annealing & 8.5 & 2.50 & 0.86 & 10.0 & 0.25 & 0.32 \\
\hline & annealed & $0.040 \mathrm{KeV}$ & +6 months & 9.2 & 2.71 & 1.8 & 10.0 & 0.22 & 0.32 \\
\hline
\end{tabular}




\subsection{Impact of annealing on non-specular scattering}

Measurements of the distribution of non-specular scattering can reveal information about interface morphology. In addition certain features, such as the Yoneda peak, ${ }^{17}$ give an indication of the angles of incidence and exit at which point the scattering volume is maximal. Figure 4 shows measurements of the non-specular scattering from the samples before annealing and at annealing +6 months.
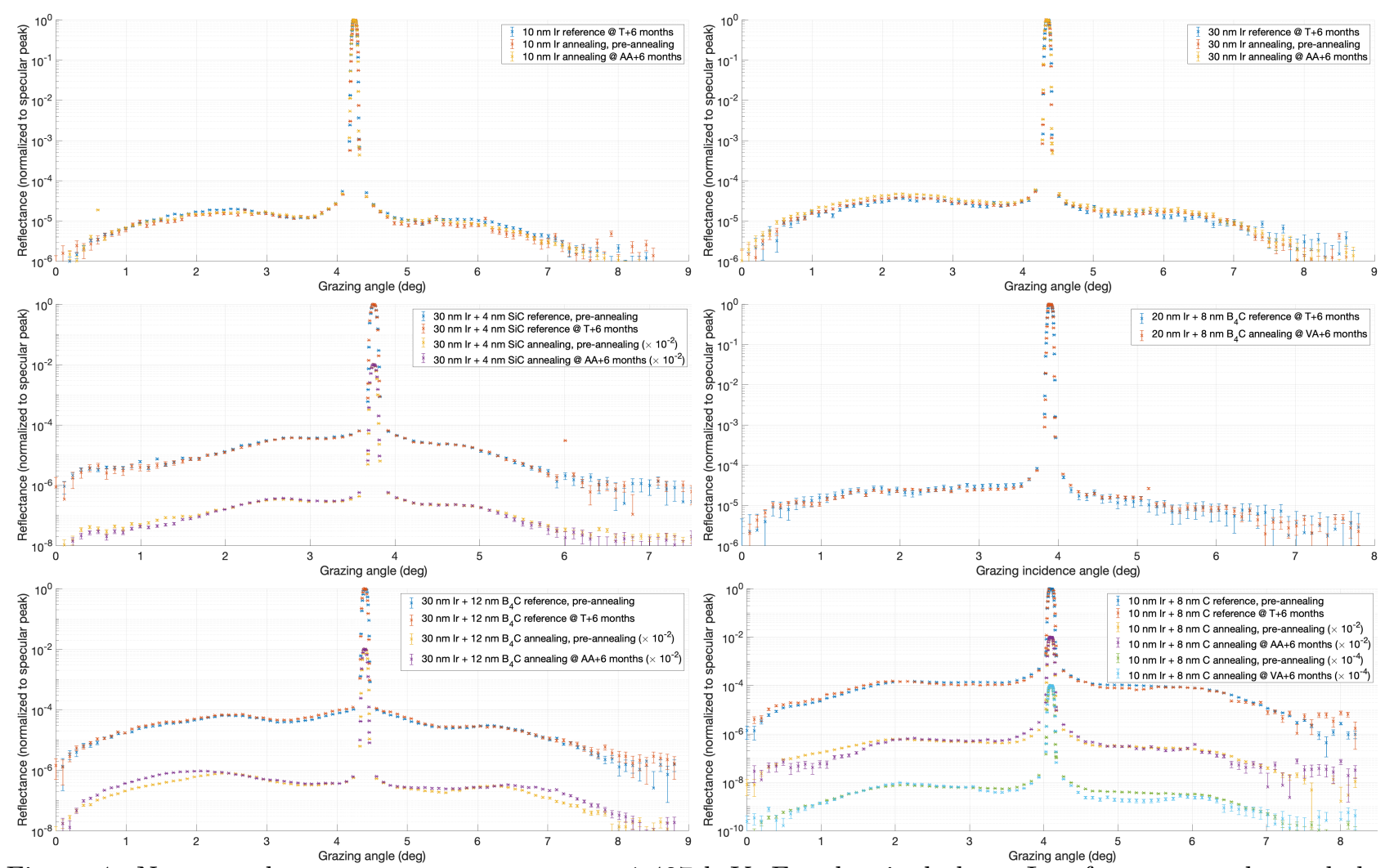

Figure 4: Non-specular scatter measurements at $1.487 \mathrm{keV}$. For the single layer Ir reference samples and the vacuum annealed $\mathrm{Ir} / \mathrm{B}_{4} \mathrm{C}$ no scatter measurements are available pre-annealing so the data has been overplotted directly. On the other samples a scaling has been used for clarity in comparing each individual sample before/after treatment.

No difference is observed in the amount of non-specular scattering from either the Ir single layers or the $\mathrm{Ir} / \mathrm{SiC}$ after annealing. The small variations on the scattering from the $\mathrm{Ir} / \mathrm{C}$ is most likely due to systematic variations in the measurement. The atmospherically annealed $\mathrm{Ir} / \mathrm{B}_{4} \mathrm{C}$ shows a clear change in the Yoneda peak after annealing, at which point the shape of the scatter function is similar to that of Ir without a low-Z overcoating, confirming the partial removal of $\mathrm{B}_{4} \mathrm{C}$ as a scattering medium on this sample. Generally, the change in fitted roughness from the specular measurements is not reflected on the scatter measurements in terms of a difference in scattering intensity compared to before annealing. This indicates that the evolution of the roughness is more related to diffuseness of the interfaces (compositional grading normal to the surface) rather than genuine roughness in the conventional sense.

\subsection{Simulated effect of overlayer degradation on specular reflectance at $1.487 \mathrm{keV}$}

The effect of a removal of the overcoating layer is primarily evident at low energies and more so for the case of thick overcoats. Figure 5 shows a simulation of the effect of a reduction of the $\mathrm{B}_{4} \mathrm{C}, \mathrm{SiC}$ and $\mathrm{C}$ layers equivalent to the effect observed on atmospherically annealed $\mathrm{B}_{4} \mathrm{C}$ (i.e a reduction in thickness, density, and roughness of $40 \%, 58 \%$, and $64 \%$ respectively) at $1.487 \mathrm{keV}$. 


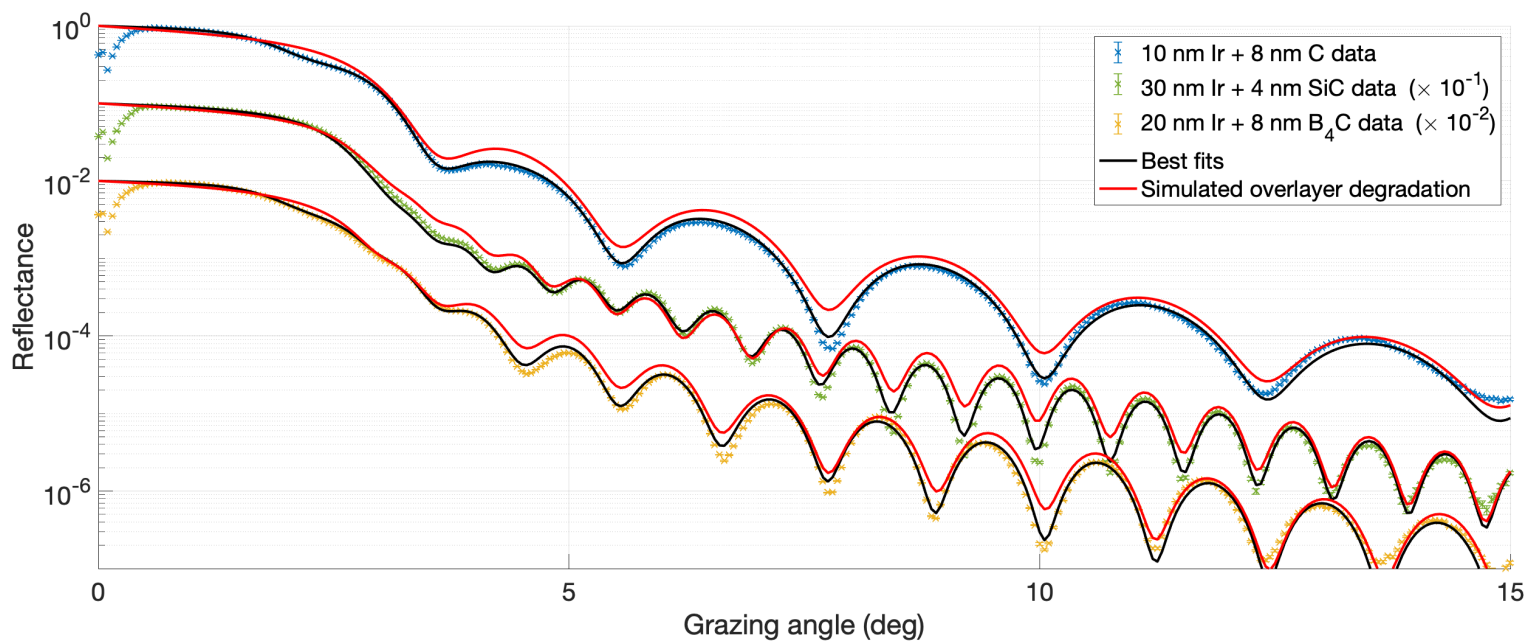

Figure 5: $1.487 \mathrm{keV}$ reflectometry data of vacuum annealed $\mathrm{Ir} / \mathrm{B}_{4} \mathrm{C}$ and atmospherically annealed $\mathrm{Ir} / \mathrm{SiC}$ and $\mathrm{Ir} / \mathrm{C}$ coated samples along with best fit models (from Table 2) and a simulation showing the effect of overlayer degradation on the sample reflectance.

The curves simulating an overlayer degradation of the same magnitude as that of the atmospherically annealed $\mathrm{B}_{4} \mathrm{C}$ are distinctly different from the measured data and fits to the vacuum annealed $\mathrm{B}_{4} \mathrm{C}$ and atmospherically annealed $\mathrm{Ir} / \mathrm{SiC}$ and $\mathrm{Ir} / \mathrm{C}$ samples. Particularly the entire $\mathrm{Ir} / \mathrm{C}$ curve is different but also on the $\mathrm{Ir} / \mathrm{B}_{4} \mathrm{C}$ can the difference be seen on the double critical angle and around $5 \mathrm{deg}$. The effect is smallest on the $\mathrm{Ir} / \mathrm{SiC}$ due to the small thickness of the layer but the region around $4 \mathrm{deg}$ and $9 \mathrm{deg}$ indicates that no such degradation on the $\mathrm{SiC}$ has taken place.

\subsection{Characterization at intermediate energies}

In addition to $\theta-2 \theta$ measurements at $1.487 \mathrm{keV}$ and $8.048 \mathrm{keV}$, the samples were measured at the FCM beamline at the PTB laboratory at BESSY II after annealing. Fits to the reference sample data at 0.6 deg yielded models that can reproduce the data of both reference and annealed samples at $0.6 \mathrm{deg}$ and $1 \mathrm{deg}$, provided small offsets in the grazing incidence angle are accounted for, as shown in Figure 6. Only the atmospherically annealed $\operatorname{Ir} / \mathrm{B}_{4} \mathrm{C}$ requires two different models to reproduce the measured data from reference and annealed samples. We see a drastic change in the shape of the reflectance curve from the removal of the $\mathrm{B}_{4} \mathrm{C}$. This effect, particularly the bumps from the $\mathrm{B}_{4} \mathrm{C}$ below $7 \mathrm{keV}$ at $0.6 \mathrm{deg}$, can not be accounted for simply by an offset in incidence angle. All other samples with an overcoat have a characteristic shape at 5-6 keV at 0.6 deg and below $4 \mathrm{keV}$ at 1 deg.

The reflectance data in the range $3.4-10 \mathrm{keV}$ is thus in agreement with the results from single-energy characterization, that only $\mathrm{B}_{4} \mathrm{C}$ annealed under ambient conditions suffers degradation. 

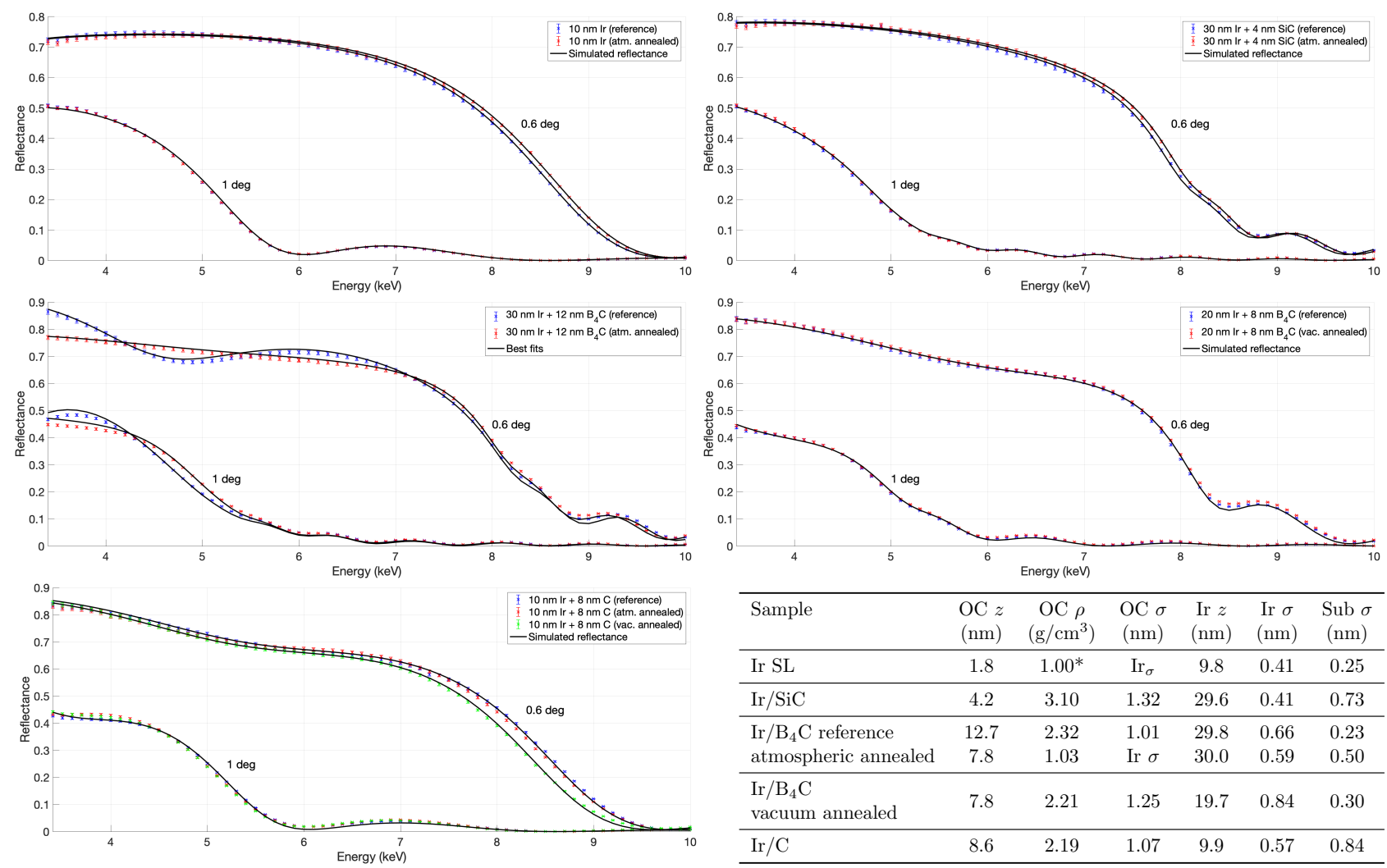

\begin{tabular}{|c|c|c|c|c|c|c|}
\hline Sample & $\begin{array}{l}\mathrm{OC} z \\
(\mathrm{~nm})\end{array}$ & $\begin{array}{c}\mathrm{OC} \rho \\
\left(\mathrm{g} / \mathrm{cm}^{3}\right)\end{array}$ & $\begin{array}{l}\mathrm{OC} \sigma \\
(\mathrm{nm})\end{array}$ & $\begin{array}{l}\operatorname{Ir} z \\
(\mathrm{~nm})\end{array}$ & $\begin{array}{l}\operatorname{Ir} \sigma \\
(\mathrm{nm})\end{array}$ & $\begin{array}{l}\text { Sub } \sigma \\
(\mathrm{nm})\end{array}$ \\
\hline Ir SL & 1.8 & $1.00^{*}$ & $\operatorname{Ir}_{\sigma}$ & 9.8 & 0.41 & 0.25 \\
\hline $\mathrm{Ir} / \mathrm{SiC}$ & 4.2 & 3.10 & 1.32 & 29.6 & 0.41 & 0.73 \\
\hline $\begin{array}{l}\mathrm{Ir} / \mathrm{B}_{4} \mathrm{C} \text { reference } \\
\text { atmospheric annealed }\end{array}$ & $\begin{array}{c}12.7 \\
7.8\end{array}$ & $\begin{array}{l}2.32 \\
1.03\end{array}$ & $\begin{array}{l}1.01 \\
\operatorname{Ir} \sigma\end{array}$ & $\begin{array}{l}29.8 \\
30.0\end{array}$ & $\begin{array}{l}0.66 \\
0.59\end{array}$ & $\begin{array}{l}0.23 \\
0.50\end{array}$ \\
\hline $\begin{array}{l}\mathrm{Ir} / \mathrm{B}_{4} \mathrm{C} \\
\text { vacuum annealed }\end{array}$ & 7.8 & 2.21 & 1.25 & 19.7 & 0.84 & 0.30 \\
\hline $\mathrm{Ir} / \mathrm{C}$ & 8.6 & 2.19 & 1.07 & 9.9 & 0.57 & 0.84 \\
\hline
\end{tabular}

Figure 6: Reflectance as function of energy for incidence angles of 0.6 and 1 deg. The simulated reflectance shown is from models with parameters listed in the table. In all cases except for atmospheric annealed $\operatorname{Ir} / \mathrm{B}_{4} \mathrm{C}$, the same model fits both reference and annealed data sets with an offset in grazing incidence angle of up to 13 mdeg. *Indicates a fixed parameter.

\section{SUMMARY}

A study was carried out on the effect that annealing at $200{ }^{\circ} \mathrm{C}$ for 50 hours has on reflectance of witness samples coated with the Athena coating material candidates. We observed a drastic degradation of the $\mathrm{B}_{4} \mathrm{C}$ when annealed under atmospheric conditions. No such degradation was observed on $\mathrm{SiC}, \mathrm{C}$, or $\mathrm{B}_{4} \mathrm{C}$ annealed under low vacuum. Simulations of the effect on reflectance curves of a degradation similar to that observed on atmospheric annealed $\mathrm{B}_{4} \mathrm{C}$ indicates that such an effect would have been identifiable on the $1.487 \mathrm{keV}$ measurements. The nature of the degradation and any compositional or structural changes in the film from thermal treatment could be evaluated by other means such as atomic force microscopy or X-ray photoelectron spectroscopy.

Based on the results of this work, subsequent studies will be carried out with the relevant coating recipes deposited on SPO plates representative for substrates to be used for Athena.

\section{ACKNOWLEDGMENTS}

This activity has been funded by the European Space Agency under contract 4000102248/10/NL/PM.

\section{REFERENCES}

[1] Nandra, K., Barret, D., Barcons, X., et al., "The Hot and Energetic Universe: A White Paper presenting the science theme motivating the Athena+ mission," astro-ph.HE arXiv:1306.2307 (2013). 
[2] Girou, D., Massahi, S., Della Monica Ferreira, D., Christensen, F., Landgraf, B., Shortt, B., Collon, M., and Beijersbergen, M., "Plasma etching for the compatibility of thin film metallic coatings and direct bonding of silicon pore optics," Journal of Applied Physics 128, 095302 (09 2020).

[3] Kern, W., "The evolution of silicon wafer cleaning technology," Journal of The Electrochemical Society 137, 1887-1892 (jun 1990).

[4] Shimbo, M., Furukawa, K., Fukuda, K., and Tanzawa, K., "Silicon-to-silicon direct bonding method," Journal of Applied Physics 60, 2987-2989 (1986).

[5] Kräuter, G., Schumacher, A., and Gösele, U., "Low temperature silicon direct bonding for application in micromechanics: bonding energies for different combinations of oxides," Sensors and Actuators A: Physical 70(3), 271-275 (1998).

[6] Singam, P. S., Nayak, M., Gupta, R., Pradhan, P. C., Majhi, A., Narendranath, S., and Sreekumar, P., "Thermal and temporal stability of W/B4C multilayer mirrors for space-based astronomical applications," Journal of Astronomical Telescopes, Instruments, and Systems 4(4), 1 - 8 (2018).

[7] Massahi, S., Christensen, F. E., Ferreira, D. D. M., Jafari, A., Svendsen, S., Henriksen, P. L., Shortt, B., Ferreira, I., Bavdaz, M., Collon, M., Landgraf, B., Girou, D., Langer, A., Schönberger, W., Wellner, T., Krumrey, M., and Cibik, L., "Installation and commissioning of the silicon pore optics coating facility for the ATHENA mission," in [Optics for EUV, X-Ray, and Gamma-Ray Astronomy IX], O'Dell, S. L. and Pareschi, G., eds., 11119, 115 - 130, International Society for Optics and Photonics, SPIE (2019).

[8] Varian Agilent SH-100 Dry Scroll Vacuum Pump, [Manual No. 699904340 Revision E,] (2004).

[9] Henriksen, P. L., Christensen, F. E., Massahi, S., Ferreira, D. D. M., Svendsen, S., Gellert, N., Vu, L. M., Jegers, A. S., and Shortt, B., "Qualification and performance of the Low-Energy X-ray Reflectometer (LEXR)," in [Space Telescopes and Instrumentation 2020: Ultraviolet to Gamma Ray], den Herder, J.-W. A., Nikzad, S., and Nakazawa, K., eds., 11444, 698 - 712, International Society for Optics and Photonics, SPIE (2020).

[10] Krumrey, M. and Ulm, G., "High-accuracy detector calibration at the ptb four-crystal monochromator beamline," Nuclear Instruments and Methods in Physics Research Section A: Accelerators, Spectrometers, Detectors and Associated Equipment 467-468, 1175-1178 (2001). Proceedings of the 7th Int. Conf. on Synchrotron Radiation Instrumentation.

[11] Windt, D. L., "'IMD - Software for modeling the optical properties of multilayer films", Computers in Physics 12(360) (1998).

[12] Henke, B., Gullikson, E., , and Davis, J., "X-ray interactions: photoabsorption, scattering, transmission, and reflection at e=50-30000 ev, z=1-92," Atomic Data and Nuclear Data Tables 54, 181-342 (July 1993).

[13] Lin, C.-H., [Oxidation (of Silicon)], 1584-1584, Springer US, Boston, MA (2008).

[14] Svendsen, S., Ferreira, D. D. M., Massahi, S., Henriksen, P. L., Gellert, N. C., jegers, A. S., Christensen, F. E., Landgraf, B., A., T., Collon, M. J., Ferreira, I., Shortt, B., and Bavdaz, M., "Compatibility of iridium thin films with the silicon pore optics stacking process for Athena," Proceedings of Spie 11822, International Society for Optics and Photonics, SPIE (2021).

[15] Svendsen, S., Ferreira, D. D. M., Massahi, S., Jafari, A., Gellert, N. C., Christensen, F. E., Henriksen, P. L., Vu, L. M., Jegers, A. S., Shortt, B., Landgraf, B., Girou, D. A., Collon, M. J., Cibik, L., Handick, E., and Krumrey, M., "Status of the Ir and Ir/SiC coating development for the Athena optics," in [Space Telescopes and Instrumentation 2020: Ultraviolet to Gamma Ray], den Herder, J.-W. A., Nikzad, S., and Nakazawa, K., eds., 11444, 713 - 729, International Society for Optics and Photonics, SPIE (2020).

[16] Ferreira, D. D. M., Svendsen, S., Massahi, S., Jafari, A., Vu, L. M., Korman, J., Gellert, N. C., Christensen, F. E., Kadkhodazadeh, S., Kasama, T., Shortt, B., Bavdaz, M., Collon, M. J., Landgraf, B., Krumrey, M., Cibik, L., Schreiber, S., and Schubert, A., "Performance and stability of mirror coatings for the ATHENA mission," in [Space Telescopes and Instrumentation 2018: Ultraviolet to Gamma Ray], den Herder, J.-W. A., Nikzad, S., and Nakazawa, K., eds., 10699, 916 - 926, International Society for Optics and Photonics, SPIE (2018).

[17] Yoneda, Y., "Anomalous surface reflection of x rays," Phys. Rev. 131, 2010-2013 (Sep 1963). 